\title{
Fixed Point Theorems for Occasionally Weakly Compatible Maps in Fuzzy Metric Spaces
}

\author{
Manish Jain \\ Department of \\ Mathematics, \\ Ahir College, Rewari, \\ Haryana, India.
}

\author{
Sanjay Kumar \\ Department of Mathematics, \\ D.C.R.U.S.T., \\ Haryana, India.
}

\author{
Satish Kumar \\ Department of \\ Mathematics, \\ M.D.U.P.G.R.C., \\ Mirpur, Rewari, Haryana, \\ India.
}

\begin{abstract}
The aim of this paper is to establish some common fixed point theorems under occasionally weakly compatible maps using implicit functions.
\end{abstract}

Keywords: Occasionally weakly compatible maps (owc), implicit functions.

\section{INTRODUCTION}

Zadeh [19] introduced the concept of fuzzy set as a new way to represent vagueness in our everyday life. A fuzzy set A in $\mathrm{X}$ is a function with domain $\mathrm{X}$ and values in $[0,1]$.The development of fuzzy sets lead to develop a lot of literature regarding the theory of fuzzy sets and its applications. However, when the uncertainty is due to fuzziness rather than randomness, as in the measurement of an ordinary length, it seems that the concept of a fuzzy metric space is more suitable.

There are many viewpoints of the notion of the metric space in fuzzy topology. We can divide them into following two groups:

The first group involves those results in which a fuzzy metric on a set $\mathrm{X}$ is treated as a map $\mathrm{d}: \mathrm{X} \times \mathrm{X} \rightarrow \mathrm{R}^{+}$where $\mathrm{X}$ represents the totality of all fuzzy points of a set and satisfy some axioms which are analogous to the ordinary metric axioms. Thus, in such an approach numerical distances are set up between fuzzy objects. On the other hand in second group, we keep those results in which the distance between objects is fuzzy and the objects themselves may or may not be fuzzy.

Especially, Erceg[6], Kaleva and Seikkala[13] , Kramosil and Michalek [12] have introduced the concept of fuzzy metric space in different ways. Grabiec[8] followed Kramosli and Michalek[12] and obtained the fuzzy version of Banach contraction principle. Grabiec[8] results were further generalized for a pair of commuting mappings by Subramanyam[17]. Moreover, George and Veermani[9] modified the concept of fuzzy metric spaces, introduced by Kramosil and Michalek[12]. Further, George and Veermani introduced the concept of Hausdorff topology on fuzzy metric spaces and showed that every metric induces a fuzzy metric.

We state some basic preliminaries before proceeding to our main results.

\section{PRELIMINARIES}

Definition 1.1. A fuzzy set $A$ in $X$ is a function with domain $\mathrm{X}$ and values in $[0,1]$.
Definition 1.2. [16] A binary operation * : $[0,1] \times[0,1] \rightarrow$ $[0,1]$ is a continuous t-norm if $([0,1], *)$ is a topological abelian monoid with unit 1 such that $\mathrm{a} * \mathrm{~b} \leq \mathrm{c} * \mathrm{~d}$ whenever $\mathrm{a} \leq \mathrm{c}$ and $\mathrm{b} \leq \mathrm{d}$, for all $\mathrm{a}, \mathrm{b}, \mathrm{c}, \mathrm{d} \in[0,1]$.

Example 1.1. (i) $*(a, b)=a b$,

$$
\text { (ii) } *(a, b)=\min .(a, b) \text {. }
$$

Definition 1.3.[12] The 3-tuple $(X, M, *)$ is called a fuzzy metric space (shortly, FM-Space) if $\mathrm{X}$ is an arbitrary set, * is a continuous t-norm and $\mathrm{M}$ is a fuzzy set on $\mathrm{X}^{2} \times[0, \infty)$ satisfying the following conditions:

(FM-1) $\mathrm{M}(\mathrm{x}, \mathrm{y}, 0)=0$,

$(\mathrm{FM}-2) \mathrm{M}(\mathrm{x}, \mathrm{y}, \mathrm{t})=1, \forall \mathrm{t}>0$ iff $\mathrm{x}=\mathrm{y}$,

$(F M-3) M(x, y, t)=M(y, x, t)$,

(FM-4) M(x, y, t) *M(y, z, s) $\leq M(x, z, t+s)$,

$($ FM-5) $M(x, y,):.[0,1) \rightarrow[0,1]$ is left continuous, for $x, y$, $\mathrm{z} \in \mathrm{X}$ and $\mathrm{s}, \mathrm{t}>0$.

Note that $M(x, y, t)$ can be thought of as the degree of nearness between $\mathrm{x}$ and $\mathrm{y}$ with respect to $\mathrm{t}$. We identify $\mathrm{x}=\mathrm{y}$ with $\mathrm{M}(\mathrm{x}, \mathrm{y}, \mathrm{t})=1$ for all $\mathrm{t}>0$ and $\mathrm{M}(\mathrm{x}, \mathrm{y}, \mathrm{t})=0$ with $\mathrm{t}=0$. Since $*$ is a continuous t-norm, it follows from (FM-4) that the limit of the sequence in FM-Space is uniquely determined.

In 1994, George and Veeramani[9], modified the definition 1.3 and defined Hausdorff topology on fuzzy metric space.

Definition 1.4: [9] The 3-tuple (X, M, *) is called a fuzzy metric space if $\mathrm{X}$ is an arbitrary set, $*$ is a continuous t-norm and $\mathrm{M}$ is a fuzzy set on $\mathrm{X}^{2} \times[0, \infty)$ satisfying the following conditions:

(i) $\mathrm{M}(\mathrm{x}, \mathrm{y}, 0)>0$,

(ii) $\mathrm{M}(\mathrm{x}, \mathrm{y}, \mathrm{t})=1$ iff $\mathrm{x}=\mathrm{y}$,

(iii) $M(x, y, t)=M(y, x, t)$,

(iv) $\mathrm{M}(\mathrm{x}, \mathrm{y}, \mathrm{t}) * \mathrm{M}(\mathrm{y}, \mathrm{z}, \mathrm{s}) \leq \mathrm{M}(\mathrm{x}, \mathrm{z}, \mathrm{t}+\mathrm{s})$,

(v) $\mathrm{M}(\mathrm{x}, \mathrm{y},):.(0, \infty) \rightarrow[0,1]$ is continuous, 
for $\mathrm{x}, \mathrm{y}, \mathrm{z} \in \mathrm{X}$ and $\mathrm{s}, \mathrm{t}>0$.

We consider $M$ to be fuzzy metric space in accordance with definition 1.3, with the following condition:

$\left(\right.$ FM-6) $\lim _{n \rightarrow \infty} M(x, y, t)=1$, for all $x, y \in X$ and $t>0$.

It is interesting to note that we can fuzzify examples of metric spaces in a natural way:

Let $(X, d)$ be a metric space. Define $a * b=a b$ for all $x, y$ in $\mathrm{X}$ and $\mathrm{t}>0$.

Define $\mathrm{M}(\mathrm{x}, \mathrm{y}, \mathrm{t})=\frac{t}{t+d(x, y)}$ for all $\mathrm{x}, \mathrm{y}$ in $\mathrm{X}$ and $\mathrm{t}>0$. Then $(\mathrm{X}, \mathrm{M}, *)$ is a fuzzy metric space and this fuzzy metric induced by a metric $\mathrm{d}$ is said to be the standard fuzzy metric.

Definition 1.5. [14] Two self maps $P$ and $S$ of a FM-space $X$ will be called z-asymptotically commuting (or simply asymptotically commuting) iff for all $\mathrm{t}>0, \lim _{\mathrm{n} \rightarrow \infty} M\left(\mathrm{PSx}_{\mathrm{n}}\right.$, $\left.\operatorname{SPx}_{\mathrm{n}}, \mathrm{t}\right)=1$, whenever $\left\{\mathrm{x}_{\mathrm{n}}\right\}$ is a sequence in $\mathrm{X}$ such that, $\lim _{n \rightarrow \infty} P x_{n}=\lim _{n \rightarrow \infty} S x_{n}=z$, for some $z$ in $X$.

We call these mapping as compatible mappings in the literature of fuzzy metric space.

Definition 1.6. [10] Two self maps are said to be weak compatible if they commute at their coincidence points.

Definition 1.7. Let $X$ be a non-empty set and $f$, $g$ be two self maps on $\mathrm{X}$. A point $\mathrm{X}$ in $\mathrm{X}$ is said to be a coincidence point of $f$ and $g$ if $f x=g x$.

A point $\mathrm{W}$ in $\mathrm{X}$ is said to be a point of coincidence of $f$ and $g$ if there exists a coincidence point $x$ in $X$ of $f$ and $g$ such that $w=f x=g x$.

Recently, Al-Thagafi and N.Shahzad[18], introduced the concept of occasionally weakly compatible maps (owc), as follows:

Definition 1.8. [18] Two self maps are said to be occasionally weakly compatible if there exists atleast one $\mathrm{x} \in$ $X$, for which $f(x)=g(x)$ implies $f g(x)=g f(x)$.

Example 1.2. Let $X=[1, \infty)$ endowed with Euclidean metric d. We define $\mathrm{M}(\mathrm{x}, \mathrm{y}, \mathrm{t})=\frac{t}{t+d(x, y)}$ for all $\mathrm{x}, \mathrm{y}$ in $\mathrm{X}, \mathrm{t}>0$. Let * be any continuous t-norm. Then $(\mathrm{X}, \mathrm{M}, *)$ is a FM-Space. Let $f$, $g$ be self maps on $X$ defined by $f(x)=4 x-3, x \in X$ and $\mathrm{g}(\mathrm{x})=\mathrm{x}^{2}, \mathrm{x} \in \mathrm{X}$. Then 1 and 3 are the only points of coincidence of $\mathrm{f}$ and $\mathrm{g}$. Also, $\mathrm{fg}(1)=1=\operatorname{gf}(1)$ but $\mathrm{fg}(3)=33$ $\neq 81=\mathrm{gf}(3)$. Clearly, $\mathrm{f}$ and $\mathrm{g}$ are owc but not weakly compatible.
Remark 1.1: Owc maps need not be weakly compatible.

Lemma 1.1: [14] If $\forall x, y \in X$ and $t>0, \quad k \in(0,1)$ such that $M(x, y, k t) \geq M(x, y, t)$, then $x=y$.

Lemma 1.2: [11] Let $X$ be a set, $f$ and $g$ be owc self maps on $X$. If $f$ and $g$ have a unique point of coincidence $w=f x=g x$, then $\mathrm{w}$ is the unique common fixed point of $\mathrm{f}$ and $\mathrm{g}$.

\section{MAIN RESULTS}

Theorem 2.1. Let $(X, M, *)$ be a fuzzy metric space with * being continuous $\mathrm{t}$-norm such that $\mathrm{t} * \mathrm{t} \geq \mathrm{t}$, for all $\mathrm{t} \in[0,1]$. Let $\mathrm{A}, \mathrm{B}$ be self maps on $\mathrm{X}$ satisfying the following:

(2.1) pair (A, B) is occasionally weakly compatible,

(2.2) there exists $q \in(0,1)$ such that

$\mathrm{M}(\mathrm{Bx}, \mathrm{By}, \mathrm{qt}) \geq \alpha \mathrm{M}(\mathrm{Ax}, \mathrm{Ay}, \mathrm{t})+$

$$
\beta \phi\left(\begin{array}{c}
M(B x, A y, t), \\
M\left(A y, B x, k_{1} t\right) * M\left(B y, A x, k_{2} t\right)
\end{array}\right),
$$

for all $\mathrm{x}, \mathrm{y} \in \mathrm{X}$, with $\mathrm{k}_{1}, \mathrm{k}_{2} \in(0,2)$ such that $\mathrm{k}_{1}+\mathrm{k}_{2}=2, \mathrm{t}$ $>0, \alpha, \beta>0, \alpha+\beta>1$ and $\quad \phi: \mathrm{R}^{2} \rightarrow[0,1]$ is a nondecreasing function in second variable such that $\phi(t, t)>t$, for $\mathrm{t}>0$,

(2.3) one of A or B is injective.

Then, A and B have a unique coincidence point and a unique common fixed point in $\mathrm{X}$.

Proof.Since the pair (A, B) is owc, there exists $x_{0} \in X$ such that

(2.4) $\mathrm{A}\left(\mathrm{x}_{0}\right)=\mathrm{B}\left(\mathrm{x}_{0}\right) \Rightarrow \mathrm{AB}\left(\mathrm{x}_{0}\right)=\mathrm{BA}\left(\mathrm{x}_{0}\right)$.

We claim that $\mathrm{x}_{0}$ is unique such that $\quad \mathrm{A}\left(\mathrm{x}_{0}\right)=\mathrm{B}\left(\mathrm{x}_{0}\right)$.

For, if let $\mathrm{y}_{0} \in \mathrm{X}$ such that

(2.5) $\quad \mathrm{A}\left(\mathrm{y}_{0}\right)=\mathrm{B}\left(\mathrm{y}_{0}\right)$.

Using (2.2),

$\mathrm{M}\left(\mathrm{Bx}_{0}, \mathrm{By} y_{0}, \mathrm{qt}\right) \geq \alpha \mathrm{M}\left(\mathrm{Ax}_{0}, \mathrm{Ay}_{0}, \mathrm{t}\right)+$

$$
\beta \phi\left(\begin{array}{c}
M\left(B x_{0}, A y_{0}, t\right), \\
M\left(A y_{0}, B x_{0}, k_{1} t\right) * M\left(B y_{0}, A x_{0}, k_{2} t\right)
\end{array}\right)
$$

Taking $\mathrm{k}_{1}=1=\mathrm{k}_{2}$ and using (2.4) and (2.5),

$\mathrm{M}\left(\mathrm{Bx}_{0}, \mathrm{By} \mathrm{y}_{0}, \mathrm{qt}\right) \geq \alpha \mathrm{M}\left(\mathrm{Bx}_{0}, \mathrm{By}_{0}, \mathrm{t}\right)+$

$$
\begin{aligned}
& \beta \phi\left(\begin{array}{c}
M\left(B x_{0}, B y_{0}, t\right), \\
M\left(B y_{0}, B x_{0}, t\right) * M\left(B y_{0}, B x_{0}, t\right)
\end{array}\right) \\
\geq & \alpha \mathrm{M}\left(\mathrm{Bx}_{0}, \mathrm{By}_{0}, \mathrm{t}\right)+
\end{aligned}
$$




$$
\begin{array}{r}
\beta \phi\left(\begin{array}{l}
M\left(B x_{0}, B y_{0}, t\right), \\
M\left(B y_{0}, B x_{0}, t\right)
\end{array}\right) \\
>\alpha \mathrm{M}\left(\mathrm{Bx}_{0}, \mathrm{By}_{0}, \mathrm{t}\right)+ \\
\beta \mathrm{M}\left(\mathrm{Bx}_{0}, \mathrm{By}_{0}, \mathrm{t}\right) \\
=(\alpha+\beta) \mathrm{M}\left(\mathrm{Bx}_{0}, \mathrm{By}_{0}, \mathrm{t}\right)
\end{array}
$$

This implies $\mathrm{Bx}_{0}=\mathrm{By}_{0}$, since $(\alpha+\beta)>1$. Therefore, $\mathrm{Ax}_{0}=$ $\mathrm{Bx}_{0}=\mathrm{By}_{0}=\mathrm{Ay}_{0}$.

Now, either $A$ or $B$ is injective, in either case, $\quad x_{0}=y_{0}$. Hence, $\mathrm{x}_{0}$ is the unique coincidence point of $\mathrm{A}$ and $\mathrm{B}$. Let, $\mathrm{Ax}_{0}=\mathrm{Bx}_{0}=\mathrm{k}$ (say), then $\mathrm{k}$ is the unique point of coincidence.

Then using lemma $1.2, \mathrm{k}$ is the unique common fixed point of $\mathrm{A}$ and $\mathrm{B}$.

Theorem 2.2. Let $(\mathrm{X}, \mathrm{M}, *)$ be a fuzzy metric space with * being continuous $\mathrm{t}$-norm such that $\mathrm{t} * \mathrm{t} \geq \mathrm{t}$, for all $\mathrm{t} \in[0,1]$. Let A, B be self maps on X satisfying (2.1) and (2.3) along with the following condition:

(2.6) there exists $q \in(0,1)$ such that

$\mathrm{M}(\mathrm{Bx}, \mathrm{By}, \mathrm{qt}) \geq \alpha \mathrm{M}(\mathrm{Ax}, \mathrm{Ay}, \mathrm{t})+$

$$
\beta \min .\left(\begin{array}{c}
M(B x, A y, t), \\
M\left(A y, B x, k_{1} t\right) * M\left(B y, A x, k_{2} t\right)
\end{array}\right),
$$

for all $\mathrm{x}, \mathrm{y} \in \mathrm{X}$, with $\mathrm{k}_{1}, \mathrm{k}_{2} \in(0,2)$ such that $\quad \mathrm{k}_{1}+\mathrm{k}_{2}=2, \mathrm{t}$ $>0, \alpha, \beta>0, \alpha+\beta>1$.

Then, A and B have a unique coincidence point which is the unique common fixed point of $\mathrm{A}$ and $\mathrm{B}$ in $\mathrm{X}$.

Proof: Proof immediately follows from Theorem 2.1.

Theorem 2.3: Let $(\mathrm{X}, \mathrm{M}, *)$ be a fuzzy metric space with $*$ being continuous t-norm such that $\mathrm{t} * \mathrm{t} \geq \mathrm{t}$, for all $\mathrm{t} \in[0,1]$. Let A, B be self maps on X satisfying (2.1) and (2.3) along with the following condition:

(2.7) there exists $q \in(0,1)$ such that

$\mathrm{M}(\mathrm{Bx}, \mathrm{By}, \mathrm{qt}) \geq \alpha \mathrm{M}(\mathrm{Ax}, \mathrm{Ay}, \mathrm{t})+$

$$
\beta \emptyset\left(\min .\left(\begin{array}{c}
M(B x, A y, t), \\
M\left(A y, B x, k_{1} t\right) * M\left(B y, A x, k_{2} t\right)
\end{array}\right)\right),
$$

for all $\mathrm{x}, \mathrm{y} \in \mathrm{X}$, with $\mathrm{k}_{1}, \mathrm{k}_{2} \in(0,2)$ such that $\mathrm{k}_{1}+\mathrm{k}_{2}=2$, $\mathrm{t}$ $>0, \alpha, \beta>0, \alpha+\beta>1$ and $\quad \emptyset: \mathrm{R} \rightarrow[0,1]$ is a nondecraeasing function, defined such that $\emptyset(\mathrm{t})>\mathrm{t}$, for $0<\mathrm{t} \leq$ 1.
Then, $\mathrm{A}$ and $\mathrm{B}$ have a unique coincidence point which is the unique common fixed point of $\mathrm{A}$ and $\mathrm{B}$ in $\mathrm{X}$.

Proof. Proof immediately follows from Theorem 2.2.

Theorem 2.4. Let $(\mathrm{X}, \mathrm{M}, *)$ be a fuzzy metric space with * being continuous t-norm. Let $\mathrm{A}, \mathrm{B}$ be self maps on $\mathrm{X}$ satisfying (2.1) and (2.3) along with the following condition:

(2.8) there exists $q \in(0,1)$ such that

$\mathrm{M}(\mathrm{Bx}, \mathrm{By}, \mathrm{qt}) \geq \alpha \mathrm{M}(\mathrm{Ax}, \mathrm{Ay}, \mathrm{t})+$

$$
\beta \phi\left(\begin{array}{l}
\varnothing\left(M\left(A x, B y, k_{1} t\right), M\left(A x, B x, k_{2} t\right)\right), \\
\varnothing\left(M\left(B x, A y, k_{1} t\right), M\left(B y, A y, k_{2} t\right)\right)
\end{array}\right),
$$

for all $\mathrm{x}, \mathrm{y} \in \mathrm{X}$, with $\mathrm{k}_{1}, \mathrm{k}_{2} \in(0,2)$ such that $\mathrm{k}_{1}+\mathrm{k}_{2}=2, \mathrm{t}$ $>0, \alpha, \beta>0, \alpha+\beta>1$ and $\quad \phi: \mathrm{R}^{2} \rightarrow[0,1]$ be a function such that $\phi(\mathrm{t}, 1)=\mathrm{t}, \phi(\mathrm{t}, \mathrm{t})=\mathrm{t}$, for $\mathrm{t}>0$.

Then, A and B have a unique coincidence point which is the unique common fixed point of $\mathrm{A}$ and $\mathrm{B}$ in $\mathrm{X}$.

Proof: Since the pair $(A, B)$ is owc, there exists $x_{0} \in X$ such that

(2.9) $\mathrm{A}\left(\mathrm{x}_{0}\right)=\mathrm{B}\left(\mathrm{x}_{0}\right) \Rightarrow \mathrm{AB}\left(\mathrm{x}_{0}\right)=\mathrm{BA}\left(\mathrm{x}_{0}\right)$.

We claim that $\mathrm{x}_{0}$ is unique such that $\quad \mathrm{A}\left(\mathrm{x}_{0}\right)=\mathrm{B}\left(\mathrm{x}_{0}\right)$.

For, if let $\mathrm{y}_{0} \in \mathrm{X}$ such that

(2.10) $\mathrm{A}\left(\mathrm{y}_{0}\right)=\mathrm{B}\left(\mathrm{y}_{0}\right)$.

Using (2.8),

$\mathrm{M}\left(\mathrm{Bx}_{0}, \mathrm{By} \mathrm{y}_{0}, \mathrm{qt}\right) \geq \alpha \mathrm{M}\left(\mathrm{Ax}_{0}, \mathrm{Ay}_{0}, \mathrm{t}\right)+$

$$
\beta \phi\left(\begin{array}{l}
\varnothing\left(M\left(A x_{0}, B y_{0}, k_{1} t\right), M\left(A x_{0}, B x_{0}, k_{2} t\right)\right), \\
\varnothing\left(M\left(B x_{0}, A y_{0}, k_{1} t\right), M\left(B y_{0}, A y_{0}, k_{2} t\right)\right)
\end{array}\right)
$$

Taking $\mathrm{k}_{1}=1=\mathrm{k}_{2}$ and using (2.9), (2.10)

$\mathrm{M}\left(\mathrm{Bx}_{0}, \mathrm{By}_{0}, \mathrm{qt}\right) \geq \alpha \mathrm{M}\left(\mathrm{Bx}_{0}, \mathrm{By}_{0}, \mathrm{t}\right)+$

$$
\begin{aligned}
& \beta \phi\left(\begin{array}{l}
\left.\varnothing\left(M\left(B x_{0}, B y_{0}, t\right), M\left(B x_{0}, B x_{0}, t\right)\right)\right) \\
\varnothing\left(M\left(B x_{0}, B y_{0}, t\right), M\left(B y_{0}, B y_{0}, t\right)\right)
\end{array}\right) \\
& =\alpha \mathrm{M}\left(\mathrm{Bx}_{0}, \mathrm{By}_{0}, \mathrm{t}\right)+ \\
& \beta \phi\left(\begin{array}{l}
\varnothing\left(M\left(B x_{0}, B y_{0}, t\right), 1\right), \\
\varnothing\left(M\left(B x_{0}, B y_{0}, t\right), 1\right)
\end{array}\right) \\
& =\alpha \mathrm{M}\left(\mathrm{Bx}_{0}, \mathrm{By}_{0}, \mathrm{t}\right)+ \\
& \beta \phi\left(\begin{array}{c}
M\left(B x_{0}, B y_{0}, t\right), \\
M\left(B x_{0}, B y_{0}, t\right)
\end{array}\right) \\
& =\alpha \mathrm{M}\left(\mathrm{Bx}_{0}, \mathrm{By}_{0}, \mathrm{t}\right)+ \\
& \beta \mathrm{M}\left(\mathrm{Bx}_{0}, \mathrm{By}_{0}, \mathrm{t}\right) \\
& =(\alpha+\beta) \mathrm{M}\left(\mathrm{Bx}_{0}, \mathrm{By}_{0}, \mathrm{t}\right)
\end{aligned}
$$


This implies $\mathrm{Bx}_{0}=\mathrm{By}_{0}$, since $(\alpha+\beta)>1$.

Therefore, $\mathrm{Ax}_{0}=\mathrm{Bx}_{0}=\mathrm{By}_{0}=\mathrm{Ay}_{0}$.

Since, either A or B is injective, it follows in both the cases that $\mathrm{x}_{0}=\mathrm{y}_{0}$.

Hence, $\mathrm{x}_{0}$ is unique coincidence point of $\mathrm{A}$ and $\mathrm{B}$.

Let $\mathrm{Ax}_{0}=\mathrm{Bx}_{0}=\mathrm{k}$ (say), using lemma 1.2, $\mathrm{k}$ is unique common fixed point of $\mathrm{A}$ and $\mathrm{B}$.

Further, it follows $\mathrm{x}_{0}=\mathrm{k}$.

Cor. 2.1. Let (X, M, *) be a fuzzy metric space and A, B be self maps on $\mathrm{X}, *$ being continuous t-norm. We consider (2.1), (2.3) and (2.8) with a slight modification in the definition of $\phi$, we redefine $\phi$ as follows:

$\phi\left(\mathrm{t}_{1}, \mathrm{t}_{2}\right)=\min .\left\{\mathrm{t}_{1}, \mathrm{t}_{2}\right\}$, for $\mathrm{t}_{1}, \mathrm{t}_{2} \in \mathrm{R}$.

Then, A and B have a unique coincidence point which is the unique common fixed point of $\mathrm{A}$ and $\mathrm{B}$ in $\mathrm{X}$.

Theorem 2.5. Let $(\mathrm{X}, \mathrm{M}, *)$ be a fuzzy metric space and A, $\mathrm{B}, \mathrm{P}, \mathrm{Q}$ be four self maps on $\mathrm{X}$. We assume the following:

(2.11) pairs (A, P), (B, Q) are occasionally weakly compatible (owc),

(2.12) there exists $q \in(0,1)$ such that

$\mathrm{M}(\mathrm{Px}, \mathrm{Qy}, \mathrm{qt})$

$\geq \emptyset(\mathrm{M}(\mathrm{Ax}, \mathrm{By}, \mathrm{t}), \mathrm{M}(\mathrm{Ax}, \mathrm{Px}, \mathrm{t}), \mathrm{M}(\mathrm{By}, \mathrm{Qy}, \mathrm{t})$,

$\mathrm{M}(\mathrm{Ax}, \mathrm{Qy}, \alpha \mathrm{t}), \mathrm{M}(\mathrm{By}, \mathrm{Px}, \beta \mathrm{t}))$,

for all $\mathrm{x}, \mathrm{y} \in \mathrm{X}, \mathrm{t}>0$ with $\alpha, \beta \in(0,2), \alpha+\beta=2$, where $\emptyset$ : $\mathrm{R}^{5} \rightarrow[0,1]$ is a function satisfying $\varnothing(\mathrm{t}, 1,1, \mathrm{t}, \mathrm{t}) \geq \mathrm{t}$, for all $\mathrm{t}$ in $[0,1]$. Then, the maps $\mathrm{A}, \mathrm{B}, \mathrm{P}, \mathrm{Q}$ have a unique common fixed point in $\mathrm{X}$.

Proof: Since (A, P) and (B, Q) are owc, so there exists $\mathrm{x}_{0}, \mathrm{y}_{0}$ $\in X$ such that

(2.13) $\mathrm{Ax}_{0}=\mathrm{Px}_{0} \Rightarrow \mathrm{PAx}_{0}=\mathrm{APx}_{0}$ and

(2.14) $\mathrm{By}_{0}=\mathrm{Qy}_{0} \Rightarrow \mathrm{QBy}_{0}=\mathrm{BQy}_{0}$.

We claim, $\mathrm{Px}_{0}=\mathrm{Qy}_{0}$.

For, using (2.12)

$\mathrm{M}\left(\mathrm{Px}_{0}, \mathrm{Qy}_{0}, \mathrm{qt}\right)$

$\geq \varnothing\left(\mathrm{M}\left(\mathrm{Ax}_{0}, \mathrm{By}_{0}, \mathrm{t}\right), \mathrm{M}\left(\mathrm{Ax}_{0}, \mathrm{Px}_{0}, \mathrm{t}\right), \mathrm{M}\left(\mathrm{By}_{0}, \mathrm{Qy}_{0}, \mathrm{t}\right)\right.$,

$\left.\mathrm{M}\left(\mathrm{Ax}_{0}, \mathrm{Qy}_{0}, \alpha \mathrm{t}\right), \mathrm{M}\left(\mathrm{By}_{0}, \mathrm{Px}_{0}, \beta \mathrm{t}\right)\right)$
Taking $\alpha=1=\beta$ and using (2.13), (2.14)

$\mathrm{M}\left(\mathrm{Px}_{0}, \mathrm{Qy}_{0}, \mathrm{qt}\right) \geq \emptyset\left(\mathrm{M}\left(\mathrm{Px}_{0}, \mathrm{Qy}_{0}, \mathrm{t}\right), 1,1\right.$,

$$
\begin{aligned}
& \left.\mathrm{M}\left(\mathrm{Px}_{0}, \mathrm{Qy}_{0}, \mathrm{t}\right), \mathrm{M}\left(\mathrm{Px}_{0}, \mathrm{Qy}_{0}, \mathrm{t}\right)\right) \\
\geq & \mathrm{M}\left(\mathrm{Px}_{0}, \mathrm{Qy}_{0}, \mathrm{t}\right)
\end{aligned}
$$

Now, using lemma 1.1, $\mathrm{Px}_{0}=\mathrm{Qy}_{0}$ and therefore

(2.15) $\mathrm{Ax}_{0}=\mathrm{Px}_{0}=\mathrm{Qy}_{0}=\mathrm{By}_{0}=\mathrm{k}$ (say).

Then, (2.13) and (2.14) implies

(2.16) $\mathrm{Ak}=\mathrm{Pk}$,

(2.17) $\mathrm{Bk}=\mathrm{Qk}$.

Next, we claim $\mathrm{Pk}=\mathrm{Qk}$.

For, using (2.12),

$\mathrm{M}(\mathrm{Pk}, \mathrm{Qk}, \mathrm{qt})$

$\geq \emptyset(\mathrm{M}(\mathrm{Ak}, \mathrm{Bk}, \mathrm{t}), \mathrm{M}(\mathrm{Ak}, \mathrm{Pk}, \mathrm{t}), \mathrm{M}(\mathrm{Bk}, \mathrm{Qk}, \mathrm{t})$,

$$
\mathrm{M}(\mathrm{Ak}, \mathrm{Qk}, \alpha \mathrm{t}), \mathrm{M}(\mathrm{Bk}, \mathrm{Pk}, \beta \mathrm{t}))
$$

Taking $\alpha=1=\beta$ and using (2.16), (2.17)

$\mathrm{M}(\mathrm{Pk}, \mathrm{Qk}, \mathrm{qt})$

$\geq \emptyset(\mathrm{M}(\mathrm{Pk}, \mathrm{Qk}, \mathrm{t}), 1,1, \mathrm{M}(\mathrm{Pk}, \mathrm{Qk}, \mathrm{t}), \mathrm{M}(\mathrm{Pk}, \mathrm{Qk}, \mathrm{t}))$

$\geq \mathrm{M}(\mathrm{Pk}, \mathrm{Qk}, \mathrm{t})$

Now, using lemma 1.1, $\mathrm{Pk}=\mathrm{Qk}$ and therefore

(2.18) $\mathrm{Ak}=\mathrm{Pk}=\mathrm{Qk}=\mathrm{Bk}$.

At last, we prove $\mathrm{Pk}=\mathrm{k}$.

From (2.12)

$\mathrm{M}(\mathrm{Pk}, \mathrm{k}, \mathrm{qt})=\mathrm{M}\left(\mathrm{Pk}, \mathrm{Qy}_{0}, \mathrm{qt}\right)$

$\geq \emptyset\left(\mathrm{M}\left(\mathrm{Ak}, \mathrm{By} \mathrm{y}_{0}, \mathrm{t}\right), \mathrm{M}(\mathrm{Ak}, \mathrm{Pk}, \mathrm{t}), \mathrm{M}\left(\mathrm{By}_{0}, \mathrm{Qy}_{0}, \mathrm{t}\right)\right.$,

$\left.\mathrm{M}\left(\mathrm{Ak}, \mathrm{Qy} \mathrm{y}_{0}, \alpha \mathrm{t}\right), \mathrm{M}\left(\mathrm{By}_{0}, \mathrm{Pk}, \beta \mathrm{t}\right)\right)$

Taking $\alpha=1=\beta$ and using (2.16), (2.17), (2.18)

$\mathrm{M}(\mathrm{Pk}, \mathrm{k}, \mathrm{qt})$

$\geq \emptyset(\mathrm{M}(\mathrm{Pk}, \mathrm{k}, \mathrm{t}), 1,1, \mathrm{M}(\mathrm{Pk}, \mathrm{k}, \mathrm{t}), \mathrm{M}(\mathrm{Pk}, \mathrm{k}, \mathrm{t}))$

$\geq \mathrm{M}(\mathrm{Pk}, \mathrm{k}, \mathrm{t})$

Using lemma 1.1, $\mathrm{Pk}=\mathrm{k}$. Therefore, $\mathrm{Ak}=\mathrm{Pk}=\mathrm{Qk}=\mathrm{Bk}=\mathrm{k}$.

Thus, $\mathrm{k}$ is common fixed point of $\mathrm{A}, \mathrm{B}, \mathrm{P}, \mathrm{Q}$.

Uniqueness of $\mathrm{k}$ follows from (2.12). 
Theorem 2.6. Let $(X, M, *)$ be a fuzzy metric space and A, $\mathrm{B}, \mathrm{P}, \mathrm{Q}$ be four self maps on $\mathrm{X}$. We assume (2.11) with the following:

(2.19) there exists $q \in(0,1)$ such that

$\mathrm{M}(\mathrm{Px}, \mathrm{Qy}, \mathrm{qt})$

$\geq \min .\{\mathrm{M}(\mathrm{Ax}, \mathrm{By}, \mathrm{t}), \mathrm{M}(\mathrm{Ax}, \mathrm{Px}, \mathrm{t}), \mathrm{M}(\mathrm{By}, \mathrm{Qy}, \mathrm{t})$,

$\mathrm{M}(\mathrm{Ax}, \mathrm{Qy}, \alpha \mathrm{t}), \mathrm{M}(\mathrm{By}, \mathrm{Px}, \beta \mathrm{t})\}$,

for all $\mathrm{x}, \mathrm{y} \in \mathrm{X}, \mathrm{t}>0$ with $\alpha, \beta \in(0,2), \alpha+\beta=2$.

Then, the maps A, B, P, Q have unique common fixed points.

Proof: Proof follows from theorem 2.5, by taking $\emptyset\left(t_{1}, t_{2}, t_{3}\right.$, $\left.\mathrm{t}_{4}, \mathrm{t}_{5}\right)=\min .\left\{\mathrm{t}_{1}, \mathrm{t}_{2}, \mathrm{t}_{3}, \mathrm{t}_{4}, \mathrm{t}_{5}\right\}$.

Theorem 2.7. Let $(\mathrm{X}, \mathrm{M}, *)$ be a fuzzy metric space and $\mathrm{A}$, $\mathrm{B}, \mathrm{P}, \mathrm{Q}$ be four self maps on $\mathrm{X}$. We assume (2.11) with the following:

(2.20) there exists $q \in(0,1)$ such that

$\mathrm{M}(\mathrm{Px}, \mathrm{Qy}, \mathrm{qt})$

$\geq \emptyset(\min .\{\mathrm{M}(\mathrm{Ax}, \mathrm{By}, \mathrm{t}), \mathrm{M}(\mathrm{Ax}, \mathrm{Px}, \mathrm{t})$,

$\mathrm{M}(\mathrm{By}, \mathrm{Qy}, \mathrm{t}), \mathrm{M}(\mathrm{Ax}, \mathrm{Qy}, \alpha \mathrm{t}), \mathrm{M}(\mathrm{By}, \mathrm{Px}, \beta \mathrm{t})\})$,

for all $\mathrm{x}, \mathrm{y} \in \mathrm{X}, \mathrm{t}>0$ with $\alpha, \beta \in(0,2), \alpha+\beta=2$ and $\emptyset: \mathrm{R}$ $\rightarrow[0,1]$ is a function such that $\quad \emptyset(\mathrm{t})>\mathrm{t}$, for $0<\mathrm{t} \leq 1$.

Then, the maps A, B, P, Q have unique common fixed points.

Proof: Proof follows from theorem 2.6.

\section{ACKNOWLEDGEMENT}

Second author is thankful to UGC, New Delhi for providing Major Research Project under F. No. 39-41/2010(SR).

\section{REFERENCES}

[1] C.T.Aage and J.N.Salunke; On fixed point theorems in fuzzy metric spaces; Int. J. Open Problems Compt. Math., 3(2), (2010), 123-131.

[2] R.Chugh, S.Rathi and S.kumar; Common fixed point theorem for compatible mappings of type $(\mathrm{P})$ in fuzzy metric spaces, Studii Si Cercetari Stintifce, Seria Mathematica, 12(2002), 75-84.

[3] Y.J.Cho; Fixed points in fuzzy metric space; J.Fuzzy Math.,5(4),(1997),949-962.

[4] Y.J.Cho, B.K.Sharma and R.D.Sahu; Semi compatibility and fixed points; Math. Japonica, 42(1), (1995), 91.

[5] Z.K.Deng; Fuzzy pseudo-metric space; J. Math. Anal. Appl., 86(1982),74-95.

[6] M.A.Erceg; Metric space in fuzzy set theory; J. Math. Anal. Appl., 69(1979), 205-230.

[7] M. Fréchet; Sur quelques points du calcul fonctionnel; Rendiconti de Circolo Matematico di Palermo, 22(1906), 1-74

[8] M.Grabiec; Fixed points in fuzzy metric spaces; Fuzzy Sets and Systems; 27(1983),385-389.

[9] A.George and P.Veeramani; On some results in fuzzy metric spaces; Fuzzy Sets and Systems;64(1994), 395399.

[10] G.Jungck and B.E.Rhoades; Fixed point theorems for set valued functions without continuity; Indian J. Pure and Applied Math., 29(1998), 227-238.

[11] G.Jungck and B.E.Rhoades; Fixed point theorems for occasionally weakly compatible mappings; Fixed Point Theory, 7(2), (2006), 287-296.

[12] I.Kramosil and J.Michalek;Fuzzy metric and statistical metric spaces; Kybernetica, 11(1975), 326-334.

[13] O.Kaleva and S.Seikkala; On fuzzy metric spaces; Fuzzy Sets and Systems, 12(1984), 215-229.

[14] S.N.Mishra, N.Sharma and S.L.Singh; Common fixed points of maps on fuzzy metric spaces; International J. Math. Math. Sci., 17(1994), 253-258.

[15] B.Singh, S.Jain and Shobha Jain; Semi compatibility and common fixed point in fuzzy metric space; Bull. Cal. Math. Soc., 98(3),(2006), 229-236.

[16] B. Schweizer and A.Sklar; Probabilistic metric spaces; North Holland series in Probability and Applied Math., 5(1983).

[17] P.V.Subramanyam; Common fixed point theorems in fuzzy metric spaces; Infor. Sci.; 83(4) (1995), 109-112.

[18] A.Al-Thagafi and Naseer Shahzad; Generalized INonexpansive self maps and invariant approximations; Acta Mathematica Sinica, English Series; 24(5), (2008), 867-876.

[19] L.A.Zadeh; Fuzzy sets; Information and Control, 89(1965), 338-353. 